\title{
Load Switching Analysis using Converter with Optimization Algorithm in Hybrid Renewable Energy System
}

\author{
Shilpa Bharti \\ M. Tech Scholar \\ Bhopal Institute of Technology and Science (BITS), \\ Bhopal (M.P), India \\ shilpa.bharti09@gmail.com
}

\author{
Abhishek Dubey \\ Assistant professor \\ Bhopal Institute of Technology and Science (BITS), \\ Bhopal (M.P), India
}

\begin{abstract}
Recently, an increasing number of organizations have begun to view renewable energy and industries as opportunities rather than regulations in the context of their production, distribution, and services. In this paper, main objective of designing a grid integrated solar-wind hybrid energy system for driving loads for improving its reliability and efficiency. And the inverter control designing with an AI-based optimization algorithm to attain improved active power at the terminal of loading by reducing the losses. And Improvement in the reactive power output from the system by the inverter control by a designed hybrid system that can compensate the reactive power requirement when required. The active power output from the system has enhanced to $77860 \mathrm{~W}$ in the system having converter regulated from the proposed controller that is MF_DEH from 77230 as a result of improved performance and reduced losses. The system was first compared with the PI-directed inverter control and the THD\% in current, as well as voltage waveform, was found to be reduced to $0.11 \%$ in voltage and $0.41 \%$ in current from $0.86 \%$ and $1.93 \%$ respectively.
\end{abstract}

Keywords: IPCC, THD, AI, PCU, PV.

\section{INTRODUCTION}

Recently, an increasing number of organizations have begun to view renewable energy and industries as opportunities rather than regulations in the context of their production, distribution and services [1-6]. Several factors such as the Kyoto Protocol, the alarming reports from the Intergovernmental Panel on Climate Change (IPCC) and the Copenhagen Climate Change Conference (COP15) have contributed to this shift in mindset and many countries believe this trend will continue, so it is very important with them that they can prepare themselves immediately for the "green race". Indeed, the Algerian government and companies are no exception; they have recently stepped up their efforts to promote economic growth by supporting green industries. Examples of such efforts are the plans for the creation of numerous energy clusters in many areas such as the planned wind farm with a capacity of 10 megawatts, which was commissioned from Adrar, and the hybrid system in the Hassi R'Mel region. Which was launched in February 2011 was built and put into operation.

The generation of electricity from wind and photovoltaic sources is considered the most promising renewable energy, so it should be developed to replace the generation of coal, oil, gas and even nuclear. However, any process of converting energy from one usable form to another is complex and naturally involves a series of economic and ecological aspects of a different nature (the operation of large-scale renewable energies requires a space where the resource is available, which is a "good" "Even the management planning and the electricity grids are adapted and managed in such a way as to favor decentralized production). The technological, economic and ecological results obtained allow an objective evaluation of the system studied.

\section{LITERATURE REVIEW}

B. Venkatasamy et al. [1] in this article, critical research into alternative energy sources is needed to meet today's electricity needs due to the rapid utilization of fossil fuel resources. One of the most important and widely used renewable energy sources is the solar photovoltaic system. These types of inverters can generate reactive power without solar radiation; If required, the inverter can also operate in reactive power mode, even if PV power is available. Reactive power is typically required to regulate the line voltage and to maintain the power factor, which improves the load capacity of the system.

P.R. Prakash et al. [2] This article presents the average life of a wind turbine 20-25 years, but electricity is also produced after the average life of the wind turbine. However, if the wind turbine is used after this average life, the maximum power that 
can be generated is reduced due to the aging of the mechanical parts and maintenance factors.

Ahmadi S et al. [3] This article presents an efficient method based on the Hybrid Big Bang-Big Crunch (HBB-BC) algorithm for the optimal sizing of an independent hybrid power system consisting of a photovoltaic panel, a wind turbine and a battery bank. Optimization is performed to continuously meet load demand while minimizing total system cost (TPC). TPC includes all costs for the life of the system, which are converted at the start of the investment.

Aissou S et al. [4] This article introduces the model and control of the hybrid drive system. It includes wind and photovoltaic sources with battery storage that power a load via an inverter. Finally, the power control of the hybrid system is presented using the Lab VIEW software. The proposed control strategy has been experimentally implemented and practical results are presented to demonstrate the effectiveness of the proposed hybrid system.

\section{OBJECTIVE}

The work proposes to attain following key objectives from the research:

- Designing of a grid integrated solar wind hybrid energy system for driving loads for improving its reliability and efficiency.

- The inverter control designing with AI based optimization algorithm to attain improved active power at the terminal of loading by reducing the losses.

- Improvement in the reactive power output from the system by the inverter control by designed hybrid system that can compensate the reactive power requirement when required.

- The system analysis and comparison basic PI regulation control at various switching points of different types of loads.

\section{METHODOLOGY}

\section{A. PV Module modeling}

Photovoltaic energy is abundant in the environment and free of pollutants. The type of output power of the photovoltaic system depends on the geographical location. The photovoltaic system is a possible source of renewable energy with which it is possible to overcome the dependence on fossil fuels [4].

Classification of off-grid and grid-connected photovoltaic systems Photovoltaic systems are divided into two categories, ie off-grid systems and interconnected to the grid or connected to the grid. This classification of photovoltaic systems is based on their operational and functional requirements, component configurations and connection to other electrical consumers and energy sources. Furthermore, photovoltaic systems can be managed independently or connected to the public grid. They are designed for AC and / or DC operation and can be connected to energy storage systems and other alternative energy sources. As already mentioned, grid-connected photovoltaic systems are designed for parallel operation and connected to the electricity grid.

The power conditioning unit (PCU) or inverter is the main component of grid-connected PV systems that convert the direct current generated by the PV generator into alternating current that meets the grid voltage and quality requirements of the public power grid for direct use on appliances or on the public electricity grid to earn the incentive rate. If the mains is not powered, the PCU automatically cuts off power to the mains.

A bidirectional interface, placed on a distribution field or on an on-site service input, allows the alternating current generated by the photovoltaic system both to power the electrical utilities on site, and to supply the grid if the power of the photovoltaic system is greater than this load request on the site. If the electrical users are greater than the power of the photovoltaic system, especially at night and in cloudy weather, the power required by the users is obtained from the electricity supplier. This is a safety feature if the grid fails for maintenance or repair to ensure that the PV system does not continue to operate and power the public grid [9].

Grid-connected photovoltaic systems without emergency energy storage (ES) are environmentally friendly and are often supported by people due to lower maintenance requirements and costs. However, in the event of a power failure during the night or on a cloudy day, the system should shut down until mains power is available. Grid-connected photovoltaic systems with a backup operating system are generally connected to the public grid. This configuration offers several advantages such as selling excess PV generation to the grid, charging the battery system during off-peak hours, and purchasing electricity from the grid to power the loads when the PV power and battery are insufficient.

Photovoltaic cells have a single operating point where the current (I) and voltage (V) values of the cell determine the maximum output power. These values correspond to a certain resistance which is equal to $\mathrm{V} / \mathrm{I}$. A simple equivalent circuit diagram of a PV cell is shown in Fig. 4.2. 


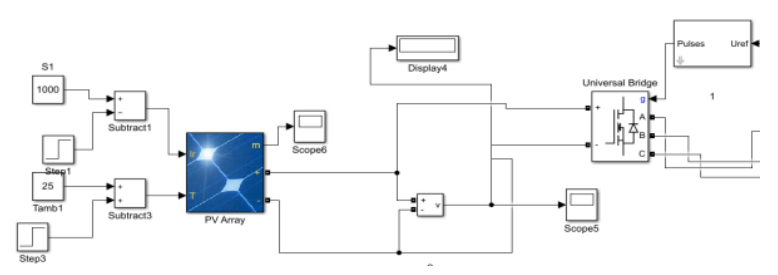

Fig. 1 Modeled solar system

A cell series resistance ( Rs ) is connected in series with parallel combination of cellphotocurrent ( $\left.\mathrm{I}_{\mathrm{ph}}\right)$, exponential diode ( D ), and shunt resistance $\left(\mathrm{R}_{\mathrm{sh}}\right)$, I pv and $\mathrm{Vpv}$ are the cells current and voltage respectively. It can be expressed as

$\begin{aligned} I_{p v}= & I_{p h}-I_{s}\left(e^{q\left(V_{p v}+I_{p v} * R_{S}\right) / n K T}-1\right)-\left(V_{p v}+I_{p v} *\right. \\ \left.R_{s}\right) / R_{s h} & \text { Eq }(3.2 .1)\end{aligned}$

Where:

$I_{p h}$-Solar-induced current

$I_{S}$ - Diode saturation current

$q$ - Electron charge $\left(1.6 \mathrm{e}^{-19} \mathrm{C}\right)$

$K$ - Boltzmann constant $\left(1.38 \mathrm{e}^{-23} \mathrm{~J} / \mathrm{K}\right)$

$n$ - Ideality factor (1 2)

$T$ - Temperature ${ }^{0} \mathrm{~K}$

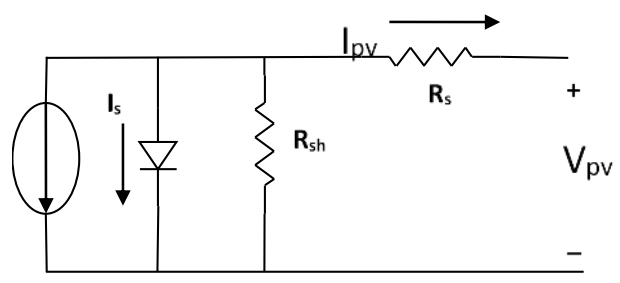

Fig. 2 Equivalent circuit of solar PV cell

The solar induced current of the solar PV cell depends on the solar irradiation level and the working temperature can be expressed as:

$I_{p h}=I_{s c}-k_{i}\left(T_{c}-T_{r}\right) * \frac{I_{r}}{1000}$

Eq (3.2.2)

Where:

$I_{S C}$ Short-circuit current of cell at STC

$k_{i}$ Cell short-circuit current/ temperature coefficient

$(\mathrm{A} / \mathrm{K})$

$I_{r}$ Irradiance in $\mathrm{w} / \mathrm{m}$

$T_{c}, T_{r}$ Cell working and reference temperature at STC

A PV cell has an exponential relationship between current and voltage and the maximum power point (MPP) occur at the knee of the curve as shown in the Fig 3.

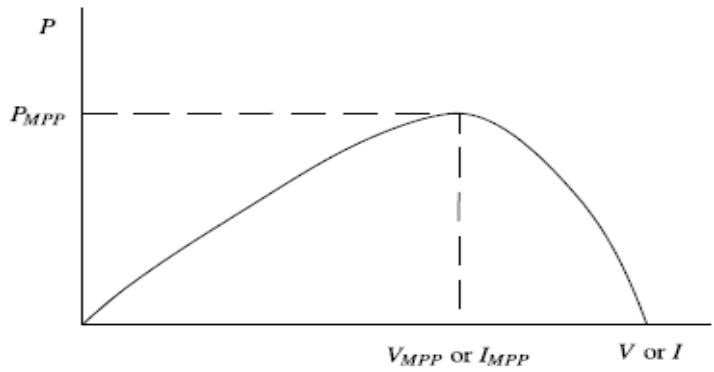

Fig. 3 Characteristic PV array power curve

Table 1 : PV module Parameters

\begin{tabular}{|l|c|}
\hline Model & 1Soltech 1STH \\
\hline Maximum Power & 213.5 Watts \\
\hline Number of parallel strings & 40 \\
\hline Number series modules & 10 \\
\hline Open circuit voltage & 36.3 Volts \\
\hline Shot circuit current & $7.84 \mathrm{Ampere}$ \\
\hline Irradiation & $1000 \mathrm{wb} / \mathrm{m}^{2}$ \\
\hline Temperature & $30^{\circ} \mathrm{C}$ \\
\hline
\end{tabular}

\section{B. Wind energy system modeling}

Wind energy is also freely available in the environment, which is an environmentally friendly energy source. The energy output from the wind turbine varies according to the wind potential of the design site. A prerequisite for a viable solution and a techno-economic wind system is the choice of a geographic location with higher wind potential [6]. The feasible and economical model of a wind power system for comparison, the performance of different wind turbines in different places is examined based on the average speed and properties of the turbines [6].

\section{Generator}

Wind energy makes two or three propellers spin around a rotor-like blade. The rotor is connected to the main shaft, which spins a generator to generate electricity. The generator thus converts the mechanical energy of the wind turbine rotor into electrical energy.

Wind turbine models with PMSG wind turbines cannot fully capture wind energy. The components of the wind turbine were modeled by the following equations [3.3.1.1-10].

Output aerodynamic power of the wind-turbine is expressed as:

$P_{\text {Turbine }}=\frac{1}{2} \rho A C_{p}(\lambda, \beta) v^{3}$

where, $\rho$ is the air density (typically $1.225 \mathrm{~kg} / \mathrm{m} 3$ ), $A$ is the area swept by the rotor blades (in $\mathrm{m} 2$ ), $C P$ is the coefficient of power conversion and $v$ is the wind speed (in $\mathrm{m} / \mathrm{s}$ ).

The tip-speed ratio is defined as:

$\lambda=\frac{\omega_{m} R}{v}$ 
where $\omega_{m}$ and $R$ are the rotor angular velocity (in $\mathrm{rad} / \mathrm{sec}$ ) and rotor radium (in $\mathrm{m}$ ), respectively.

The wind turbine mechanical torque output $m T$ given as:

$T_{m}$

$$
=\frac{1}{2} \rho A C_{p}(\lambda, \beta) v^{3} \frac{1}{\omega_{m}}
$$

The power coefficient is a nonlinear function of the tip speed ratio $\lambda$ and the blade pitch angle $\beta$ (in degrees).

Then Power output is given by

$P_{\text {Turbine }}=\frac{1}{2} \rho A C_{p_{\text {max }}} v^{3}$

A generic equation is used to model the power coefficient $C_{P}$ based on the modeling turbine characteristics described in [2], [7-9] and [11] as:

$C_{p}=\frac{1}{2}\left(\frac{116}{\lambda_{i}}-0.4 \beta-5\right) e^{-\left(\frac{21}{\lambda_{i}}\right)}$

For each wind speed, there is a specific point in the wind turbine power curve, MPPT, where power is maximized. The WECS load regulation then leads to variable speed operation of the turbine rotor, so that maximum power is continuously extracted from the wind.

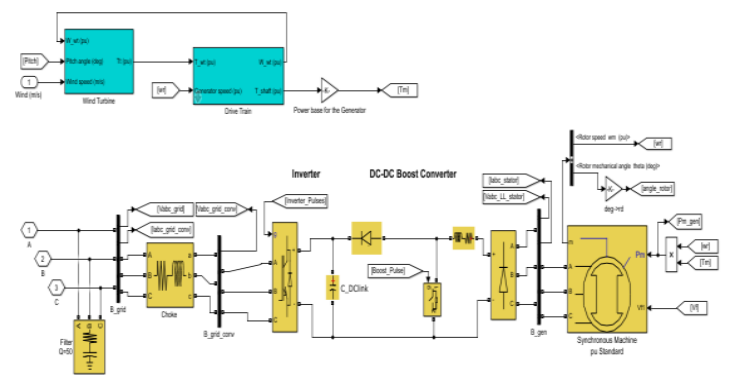

Fig. 4 modeled Wind system

This mechanism uses the variable torque output $\mathrm{w}_{\mathrm{m}}$ and tries to optimize the output current and voltage waveform to its maximum value.

Table 2 :Wind energy system parameters

\begin{tabular}{|l|l|}
\hline Wind speed & $11 \mathrm{~m} / \mathrm{sec}$ \\
\hline Number of wind turbines & 80 \\
\hline Nominal power & $2 \mathrm{MW}$ \\
\hline Frequency & $50 \mathrm{hertz}$ \\
\hline Line to line voltage & $410 \mathrm{~V}$ \\
\hline Friction factor & 0.01 \\
\hline Number of poles & 1 \\
\hline Inertia constant & 0.62 \\
\hline
\end{tabular}

D. Proposed inverter modeling and controlling algorithm

The inverter control has been designed to improve the system parameters. The design was carried out in the dq0 repository to facilitate the study of the elementary parts and their respective evolutions. The system continuously checks the variable parameters and updates them if necessary.

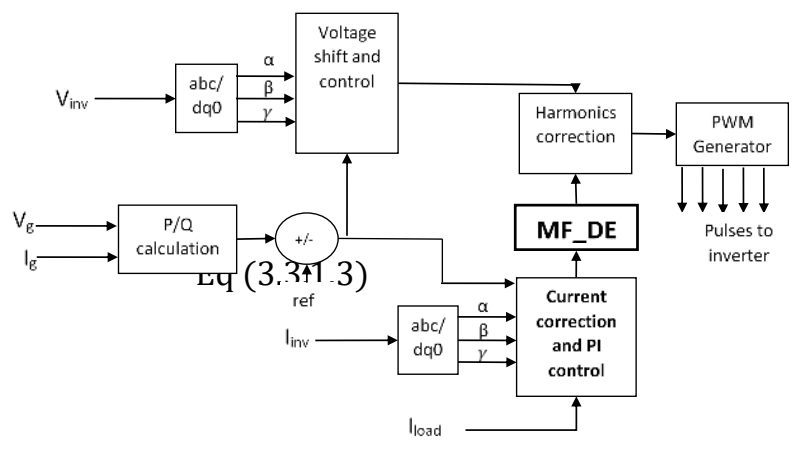

Fig. 5 differential evolutionary (DE) optimization and hysteresis band integrated PI controller for inverter

The above controller supplies pulses to the inverter, which is a three-leg 6-pulse inverter. The controller accepts grid parameters, load parameters and inverter output parameters as input. The active power and reactive power requirements have been verified and should be improved based on the modifications. Current setpoint regulation plays a decisive role in reactive power regulation by adapting the phase and load demand by adapting the gain parameter of the PI regulation. The output of the PI controller is regulated by the proposed differential evolution algorithm by performing specific iterations and achieving more optimal results. Harmonic correction occurs before the pulse generation signal is sent to the PWM generator. This multifunctional evolutionary difference heuristic optimization (MF_DEH) and the integrated hysteresis band PI controller for inverters should work and be updated at every point of the system variation to demonstrate a better pulse and thus obtain improved output parameters. The coding and performance of the DE optimization algorithm is performed in the following steps, as shown in the following flowchart:

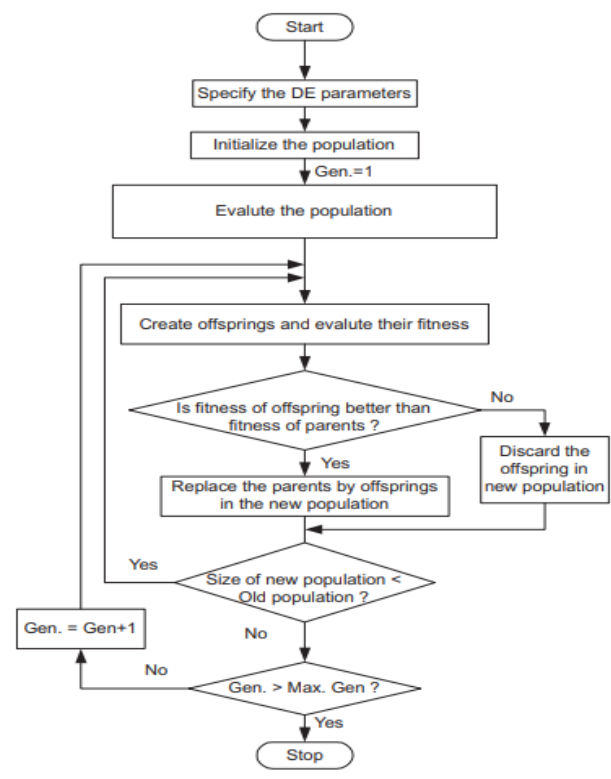


Fig. 6 Flow chart of proposed Differential Evolutionary Algorithm for converters

Differential Evolution (MF_DE) is a population-based heuristic algorithm to solve global optimization problems with different characteristics over continuous space. Despite its simplicity, it proved a great performance in solving nondifferentiable, non-continuous and multi-modal optimization problems. In simple DE, DE/rand/1/bin , an initial population of NP individuals $\overrightarrow{X_{J}}, \mathrm{j}=1,2, . ., \mathrm{NP}$, is generated at random according to a $\rho$ uniform distribution within lower and upper boundaries $\left(x_{j}^{L}, x_{j}^{U}\right)$. Individuals are evolved by the means of crossover and mutation to generate a trial vector. The trial vector competes with his parent in order to select the fittest to the next generation. The steps of MF_DEH are:

\section{E. Initialization of a population}

Initial population, as the starting point for the process of optimization, is created by assigning a random chosen value for each decision variable in every vector, as indicated in equation:

$x_{i j}^{0}=L_{j}+\operatorname{rand}_{\mathrm{j}} * \mathrm{n}\left(\mathrm{U}_{\mathrm{j}}-\mathrm{L}_{\mathrm{j}}\right)$

Where $, L_{j}, U_{j}$, arethe lower and upper boundaries for $x_{i j}$ rand $_{j}$ random number uniform $[0,1]$.

\section{F. Mutation}

A mutant vector $V_{i}^{G+1}$ is generated for each target vector $x_{i}^{G}$ at generation $\mathrm{G}$ according to equation (2)

$V_{i}^{G+1}=x_{r 1}^{G}+F *\left(x_{r 2}^{G}-x_{r 3}^{G}\right), r_{1} \neq r_{2} \neq r_{3} \neq i$

Where $\mathrm{r}_{1}, \mathrm{r}_{2}, \mathrm{r}_{3}$ are randomly chosen from the population. The mutation factor $F \in[0,2]$. A new value for the component of mutant vector is generated using (1) if it violates the boundary constraints.

\section{G. Recombination (crossover)}

Crossover is the process of swapping information between the target and the mutated individuals using (3), to yield the trial vector $u_{i}^{G+1}$

$u_{i j}^{G+1}=\left\{\begin{array}{l}v_{i j}^{G}, \operatorname{rand}(j) \leq C R \text { or } j=\operatorname{rand}(i) \\ X_{i j}^{G}, \operatorname{rand}(j)>C R \text { and } \neq \operatorname{rand}(i)\end{array}\right.$

The whole process sums up the power requirements of the system by balancing the active power of the system with the reactive power requirement of the integrated hybrid system. The system must be made efficient in terms of switching point load, effectively reducing distortion.

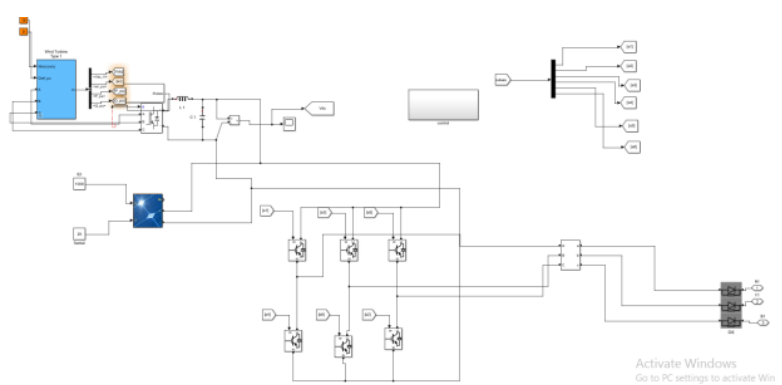

Fig. 7 Hybrid solar wind energy system with proposed MF_DEH control for three leg inverter

\section{RESUlts}

A Hybrid Power System (HPS) utilizes two or more energy sources, power converters and/or storage devices. The main purpose of HPS is to combine multiple energy sources and/or storage devices which are complement of each other. Thus, higher efficiency can be achieved by taking the advantage of each individual energy source and/or device while overcoming their limitations. In this chapter the analysis of the system having hybrid solar/wind energy system with basic PI directive control for the inverter is done.

The work first was focused on making a hybrid solar wind energy system connected to the grid. The solar system specifications as mentioned in the previous chapter were taken for analysis. The system is made to drive different types of load later. The voltage and current output in the 30Kwatt load line has been shown below.

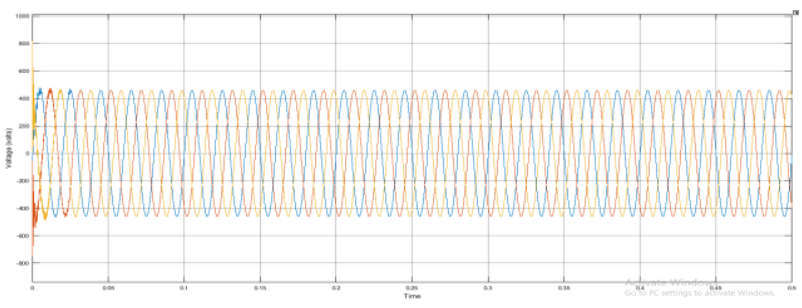

Fig. 8 Voltage available in the line with $30 \mathrm{KW}$ load

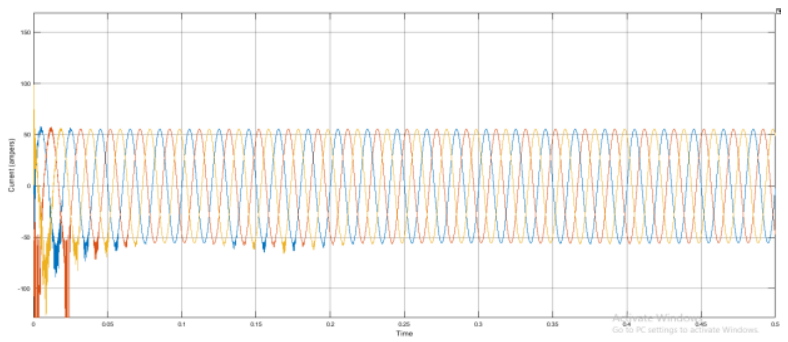

Fig. 9 Current available in the line with $30 \mathrm{KW}$ load

The output from the system is then compared with another system having solar/wind energy resources in a hybrid form and the inverter is controlled by self designed multifunction based differential evolutionary heuristic for the inverter control for enhancing all the output parameters as compared to the previous system. The chapter has discussed output from 
the hybrid system using stabilizer in the following mentioned cases:

CASE 1: Hybrid wind/solar system with basic PI directive inverter control.

CASE 2: Hybrid wind/solar system with optimization control based on multifunction differential evolutionary heuristic (MF_DEH) approach for the inverter.

CASE3: Load switching analysis with different types of loads. The system is subjected to load switching at various time intervals. The system under analysis in case one and case two is studied for variations in the new system arrived as a result of new MF_DEH control in terms of power and total harmonic distortions (THD) percentage that is measured ignoring the initial time taken by the system to overcome inertia factors.

\section{CASE 1: Hybrid wind/solar system with basic PI directive inverter control.}

The hybrid renewable energy system is created using MATLAB/SIMULINK software that is further integrated with grid. The solar PV system has DC output, hence the wind energy system three phase output AC is first converted to DC and then merged with the output of solar system. The combined DC output is fed to the inverter having PI directed control before integration with the grid energy system.

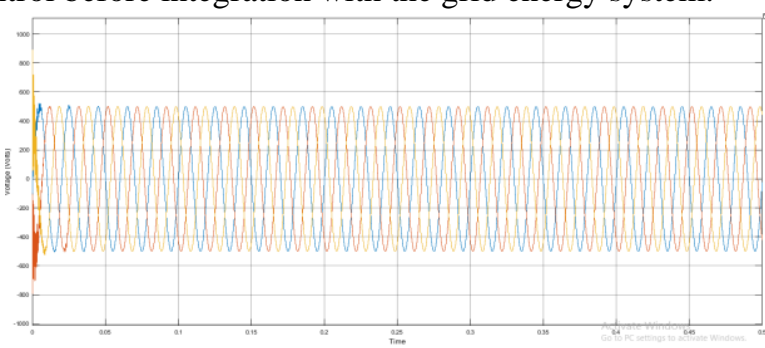

Fig. 10 Voltage output from the system at loading terminal with PI directed control

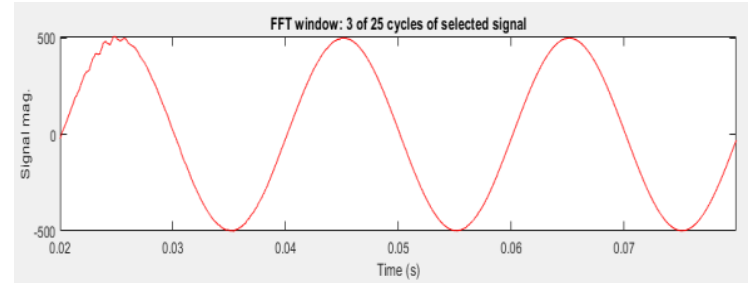

Fig. 11 FFT analysis of Voltage output from the system at loading terminal with PI directed control

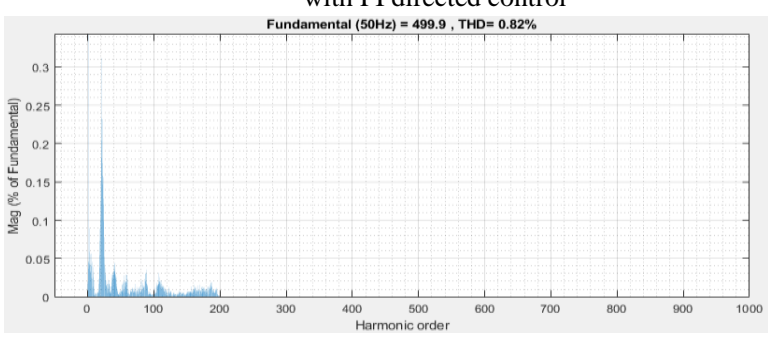

Fig. 12 THD\% in Voltage output from the system at loading terminal with PI directed control

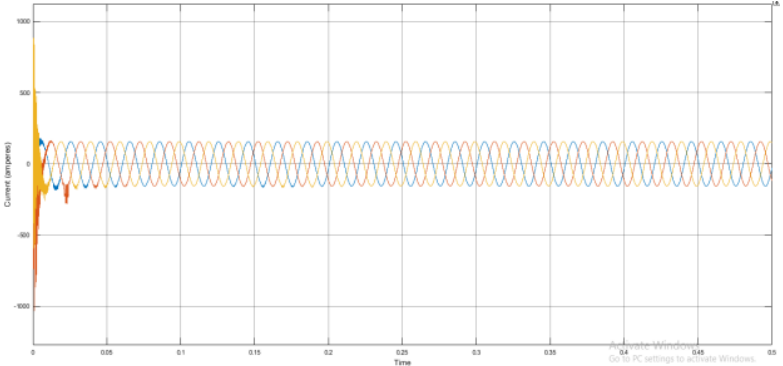

Fig. 13 Current available at loading terminal in hybrid system with PI directed control

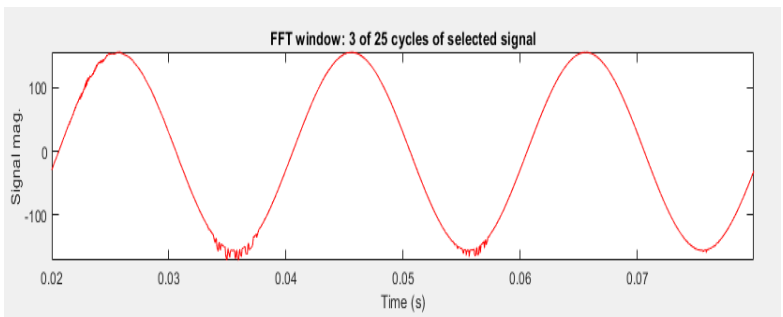

Fig. 14 FFT analysis of Current available at loading terminal in hybrid system with PI directed control

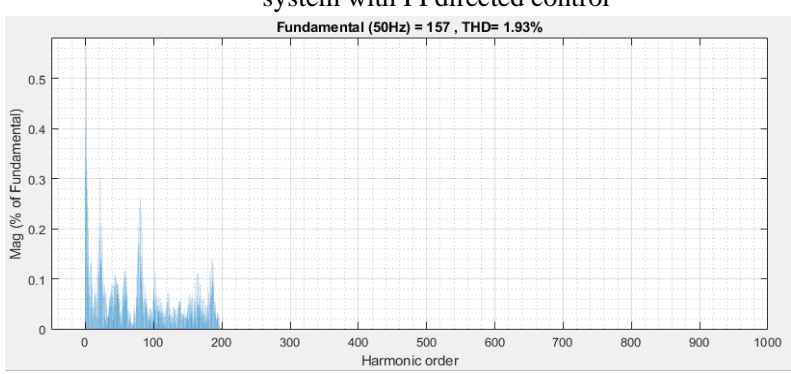

Fig. 15 THD\% in Current available at loading terminal in hybrid system with PI directed control

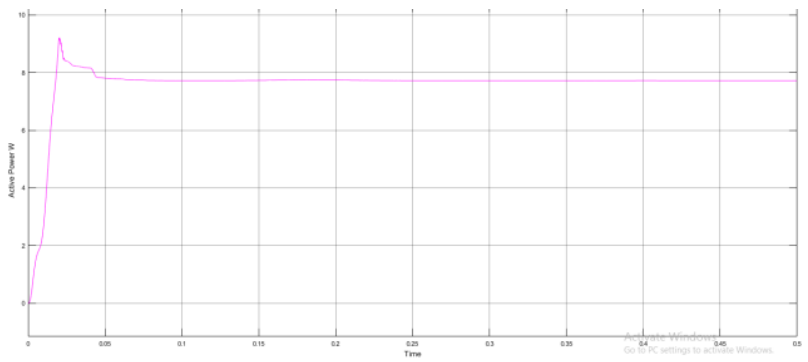

Fig. 16 Active Power available at loading terminal in hybrid system with PI directed control

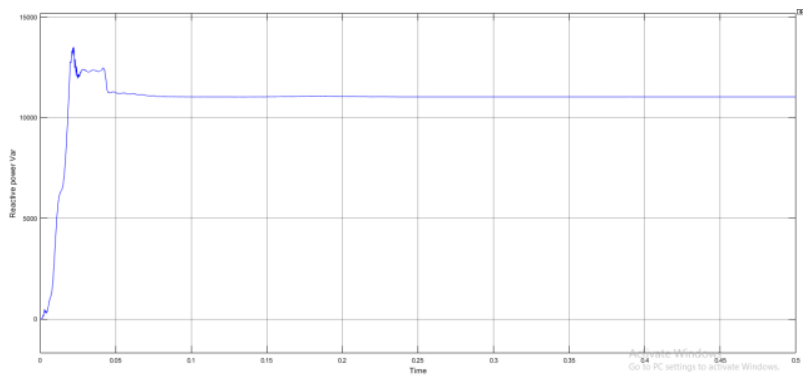

Fig. 17 Reactive power available at loading terminal in hybrid system with PI directed control

CASE 2: Hybrid wind/solar system with optimization control based on multifunction differential evolutionary heuristic (MF_DEH) approach for the inverter 
The operating line voltage for the load interconnection is maintained to be 500 volts. The system is made to drive another $30 \mathrm{KW}$ load from the system connected in parallel. The above analysis was carried out with the basic PI directive control for the inverter. In order to study the effect of our proposed controller, the same system was subjected to the proposed MF_DEH control for inverter an its effect on the current and voltage waveforms at the load terminal was analyzed. The loads in this case were constantly connected without switching.

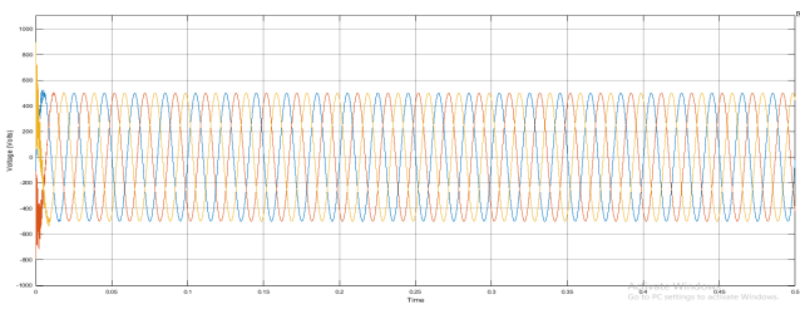

Fig. 18 Voltage output from the system at loading terminal with MF_DEH optimization control

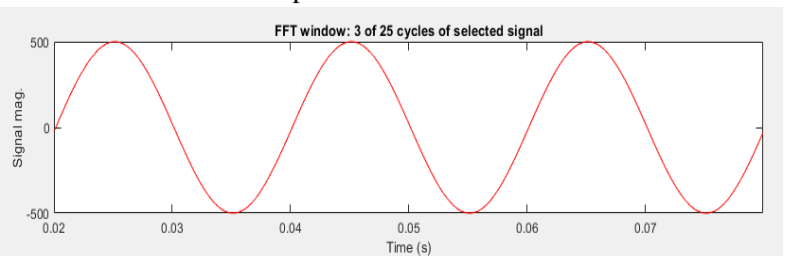

Fig. 19 FFT analysis of Voltage output from the system at loading terminal with MF_DEH optimization control

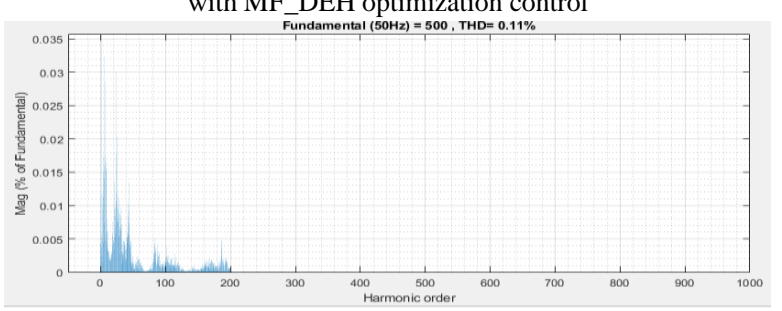

Fig. 20 THD\% in Voltage output from the system at loading terminal with MF_DEH optimization control

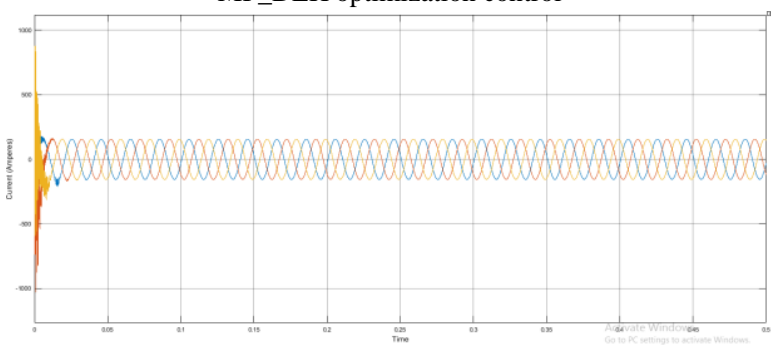

Fig. 21 Current available at the loading terminal with MF_DEH optimization control

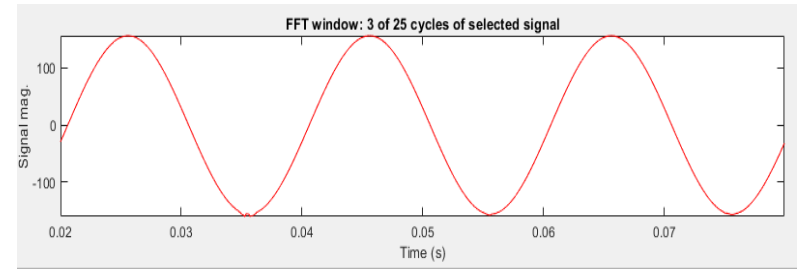

Fig. 22 FFT analysis of Current available at the loading terminal with

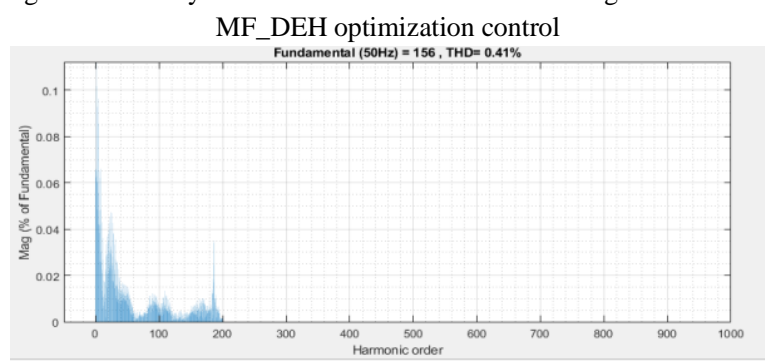

Fig. 23 THD\% of Current available at the loading terminal with MF_DEH optimization control

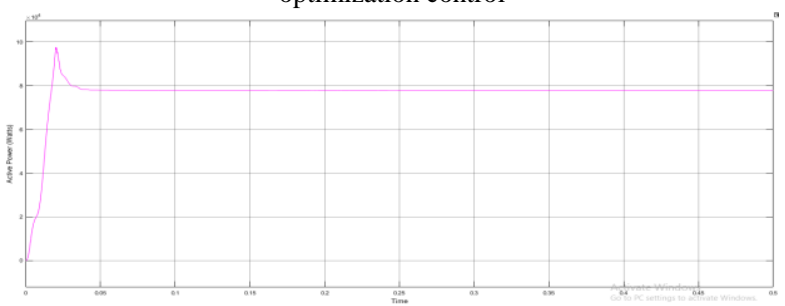

Fig. 24 Active Power available at the loading terminal with MF_DEH optimization control

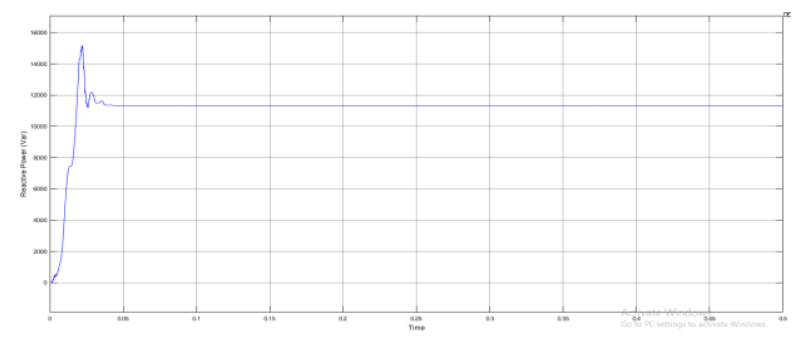

Fig. 25 Reactive Power available at the loading terminal with MF_DEH optimization control

It was concluded that by using the designed controller in the hybrid solar wind energy system the distortion level in the voltage and current waveforms was significantly reduced. This proves the efficiency of the designed controller as a total harmonic level reducer in the circuit and thereby making is more reluctant.

\begin{tabular}{|c|c|c|}
\hline \multicolumn{3}{|c|}{ Table 2 Comparative analysis of proposed controller } \\
\hline Parameters & $\begin{array}{c}\text { PI Control based } \\
\text { hybrid Solar/Wind } \\
\text { system }\end{array}$ & $\begin{array}{c}\text { Proposed controller } \\
\text { based hybrid } \\
\text { solar/wind system }\end{array}$ \\
\hline Active power & $77230 \mathrm{Watts}$ & $77860 \mathrm{Watts}$ \\
\hline Reactive power & $11040 \mathrm{Var}$ & $11300 \mathrm{Var}$ \\
\hline THD\% in voltage & $0.86 \%$ & $0.11 \%$ \\
\hline THD\% in current & $1.93 \%$ & $0.41 \%$ \\
\hline
\end{tabular}

CASE3: Load switching analysis with different types of loads

For this analysis the changes in the current waveform was analyzed at the interval when the load was switched into the lined suddenly. For this purpose three phase line breaker was used along with the $30 \mathrm{KW}$ load whose initial state remains at off condition. At 0.1 seconds the breaker switches its state to on and the load gets connected to the line. 
The line voltage remains the same that is 500 volts. The changes in the current waveform were studied by analyzing the THD level in current waveform due to sudden loading of line. The another load of inductive type (nonlinear) was switched into the line at 0.2 seconds with previous load and remains connected up to 0.5 seconds of simulation time.

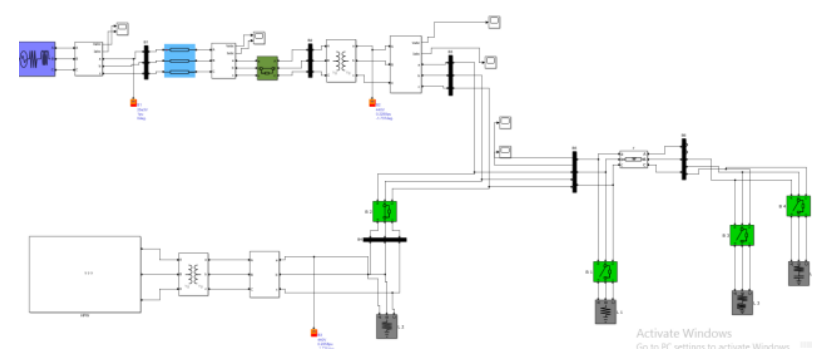

Fig. 26 Load switching model in MATLAB

The third load of capacitive type having highly variable feeding onto the line was also switched into the line at 0.2 seconds and is suddenly removed at 0.3 seconds of simulation time. The analysis is therefore carried out at three time intervals of various line switching that is $0.1,0.2$ and 0.3 seconds.

Load Switching Analysis in hybrid system with basic PI directive control

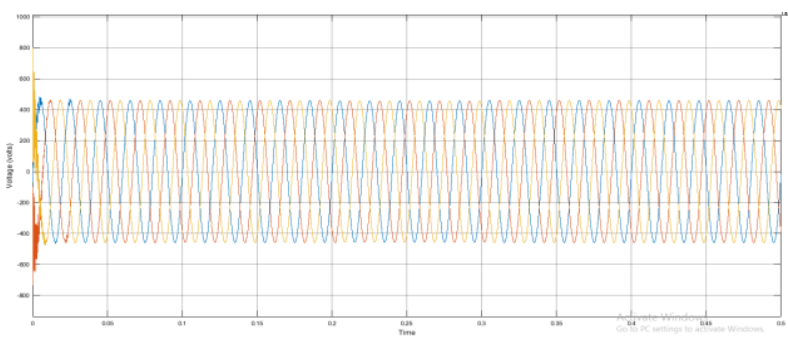

Fig. 27 Voltage output while load switching in system with PI directed control

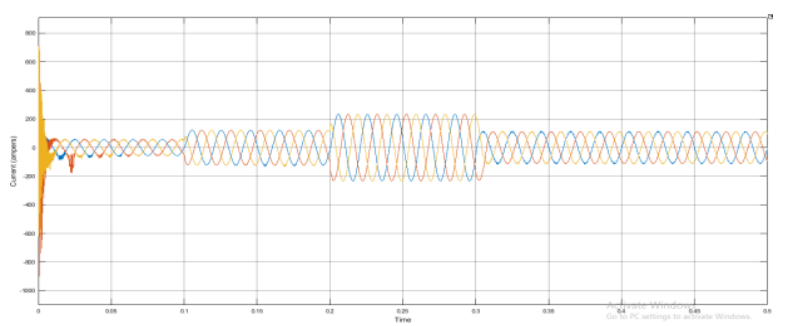

Fig. 28 Current output while load switching in system with PI directed control

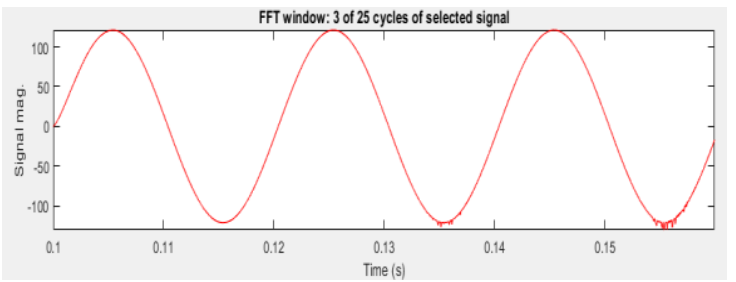

Fig. 29 FFT analysis of current at 0.1 load switching in system with PI directed control

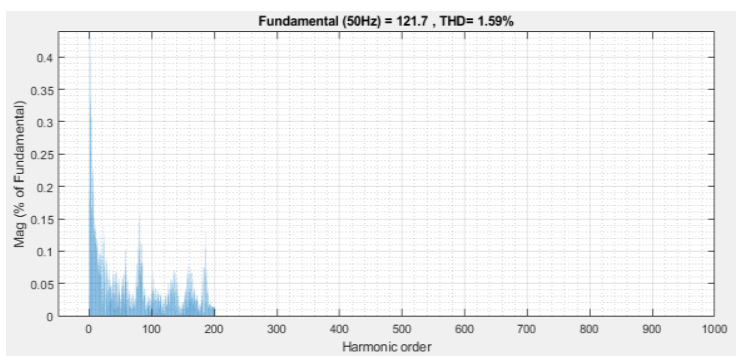

Fig. 30 THD\% of current at 0.1 load switching in system with PI directed control

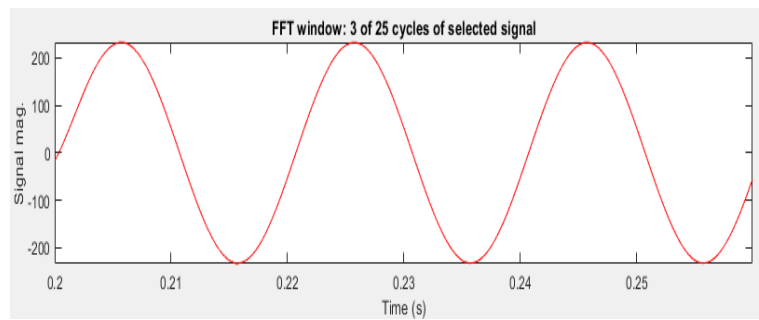

Fig. $31 \mathrm{FFT}$ analysis of current at 0.2 load switching in system with PI directed control

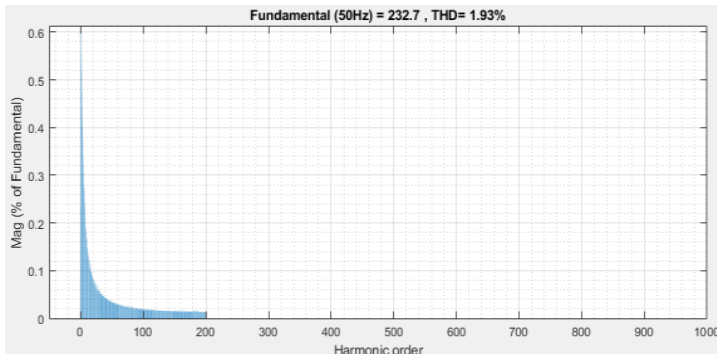

Fig. 32 THD\% of current at 0.2 load switching in system with PI directed control

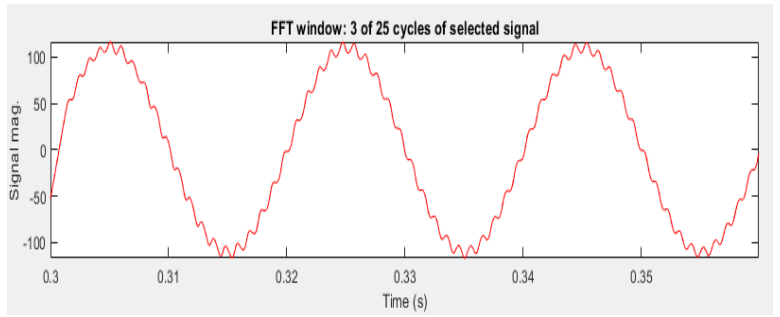

Fig. 33 FFT analysis of current at 0.3 load switching in system with PI directed control

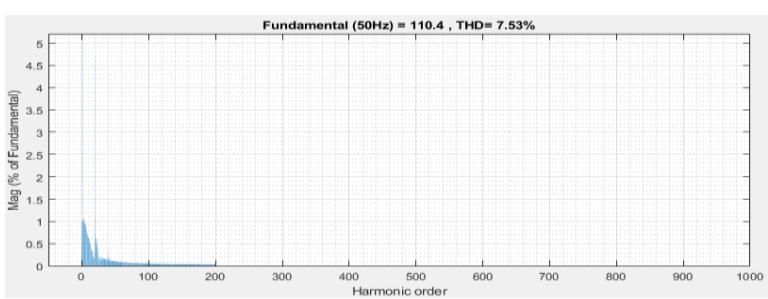

Fig. 34 THD\% of current at 0.3 load switching in system with PI directed control 
Load switching analysis of hybrid system with optimization controller MF_DEH algorithm

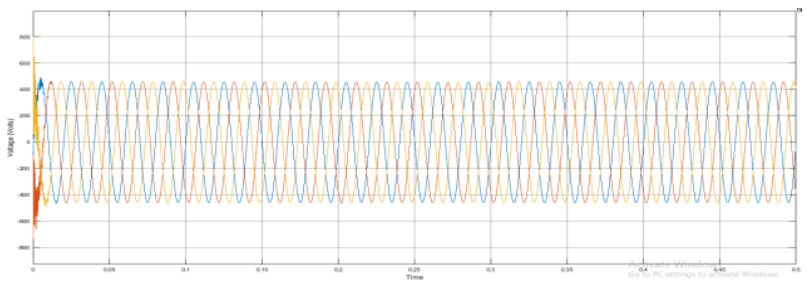

Fig. 35 Voltage output while load switching in system with MF_DEH optimization control

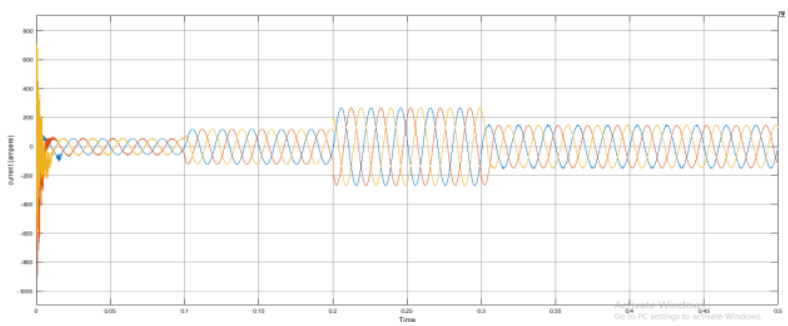

Fig. 36 Voltage output while load switching in system with MF_DEH optimization control

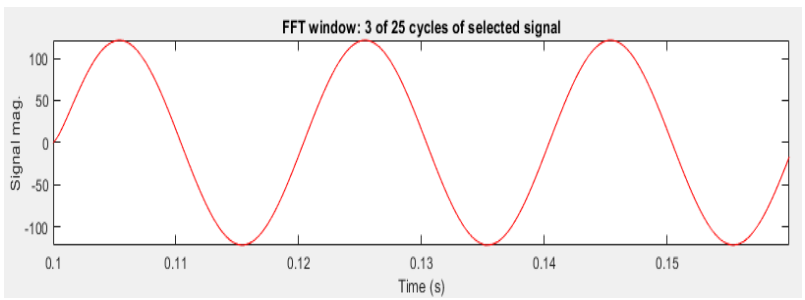

Fig. 37 FFT analysis of current at 0.1 load switching in system with MF_DEH optimization control

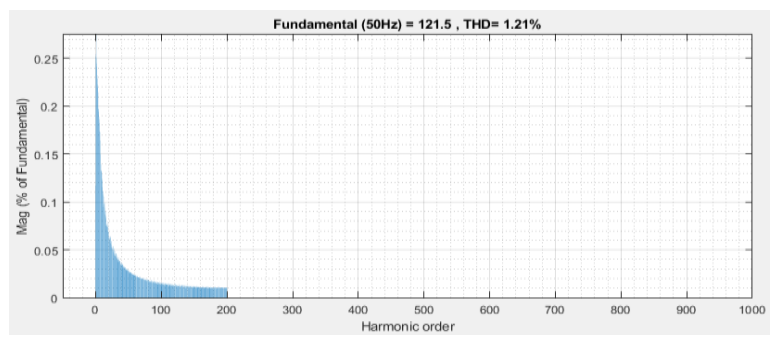

Fig. 38 THD\% of current at 0.1 load switching in system with MF_DEH optimization control

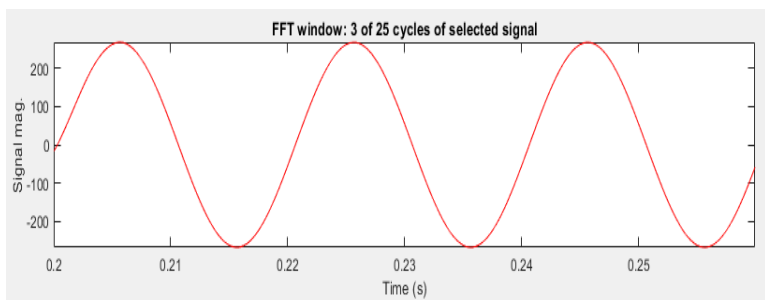

Fig. 39 FFT analysis of current at 0.2 load switching in system with MF_DEH optimization control

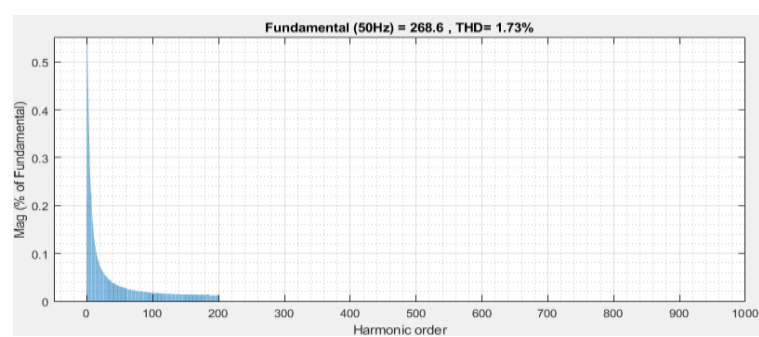

Fig. 40 THD $\%$ of current at 0.2 load switching in system with MF_DEH optimization control

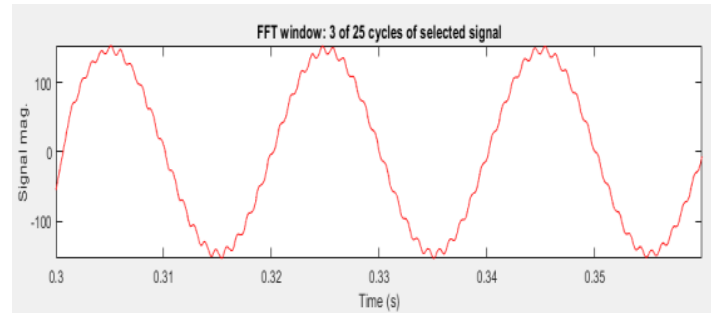

Fig. 41 FFT analysis of current at 0.3 load switching in system with MF_DEH optimization control

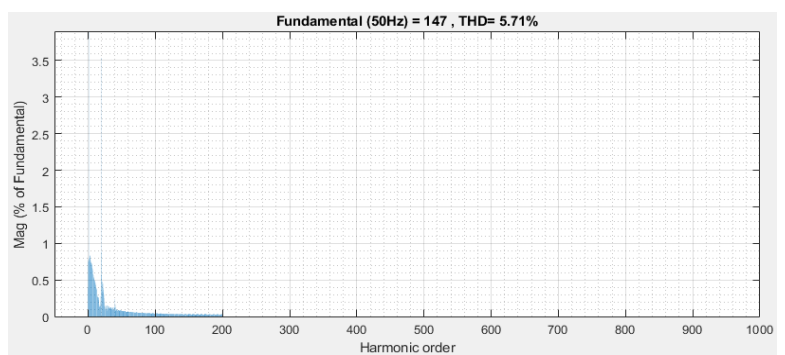

Fig. 42 THD\% of current at 0.3 load switching in system with MF_DEH optimization control

Form the above figures it can be concluded that the distortion level in the current drawn at the load terminal at the transient loading at $0.1,0.2$ and 0.3 seconds has reduced. The changes in both the system is significant and hence the designed controller has proven to be an effective choice for driving the inverter in the system. The loading was carried out with different types of loads at different points of time interval and hence the analysis is effective in driving the hybrid system in cased of dynamic working in the grid system also.

\begin{tabular}{|c|c|c|}
\hline \multicolumn{2}{|c|}{ Table 3: THD\% in current in load line loading of different types of } \\
loads
\end{tabular}

VI. CONCLUSION 
The renewable energy sources play an important role in electric power generation with growing environmental concerns. The inter connection of renewable energy sources are incorporated using power electronics converters, with the aim of improving power quality at the point of common coupling (PCC).

We have designed a controller for the converter based on the optimizing algorithm which is a part of artificial intelligence. Following main conclusions were drawn:

- The active power output from the system has enhanced to $77860 \mathrm{~W}$ in the system having converter regulated from the proposed controller that is MF_DEH from 77230 as a result of improved performance and reduced losses.

- The system was first compared with the PI directed inverter control and the THD\% in current as well as voltage waveform was found to be reduced to $0.11 \%$ in voltage and $0.41 \%$ in current from $0.86 \%$ and $1.93 \%$ respectively

- The further analysis compared the two system performance with the load switching analysis at three time intervals. The analysis concluded the effectiveness of the proposed controller in driving various loads with their sudden switching on the line.

\section{FUTURE SCOPE}

This system promotes green energy which is very important because all the energy sources are depleting day by day. So, people must look for new renewable sources and solar power is definitely one of the best choices in this purpose. In future work an adaptive neural network based control for improved power quality 3 phase grid integrated will be designed for this system having three sources in the form of solar/wind/fuel cell based hybrid system. The expected control scheme regulates the system voltage and improves the power quality in a very effective manner. The hybrid control system for can be redesigned with this control to improve its performance.

\section{REFERENCES}

[1] B. Venkatasamy, L. Kalaivani "Modeling and Power Quality Analysis of Grid-Connected PV Inverter with Active and Reactive Power Injection Mode", Journal of Electrical Engineering \& Technology 2021.

[2] P.R. Prakash, B. Venkatasamy, L. Kalaivani "Performance Analysis of Grid- Tie Inverter for Reactive Power Injection Mode in Hybrid Wind Solar Energy System", 2018 2nd International Conference on Trends in Electronics and Informatics (ICOEI), DOI:10.1109/ICOEI.2018.8553869.

[3] Ahmadi S, Abdi S (2016) "Application of the hybrid big bangbig crunch algorithm for optimal sizing of a standalone hybrid P.V./wind/battery system". Sol Energy 134:366-374.

[4] Aissou S, Rekioua D, Mezzai N, Rekioua T, Bacha S (2015) "Modeling and control of hybrid photovoltaic wind power system with battery storage". Energy Convers Manag 89:615625.

[5] Alnejaili T, Drid S, Mehdi D, Chrifi-Alaoui L, Belarbi R, Hamdouni A (2015) "Dynamic control and advanced load management of a standalone hybrid renewable power system for remote housing". Energy Convers Manag 105:377-392.

[6] Belmili H, Boulouma S, Boualem B, Fayçal A (2017) "Optimized control and sizing of standalone PV-wind energy conversion system". Energy Procedia 107:76-84.

[7] Bilal B, Sambou V, Kébé C, Ndiaye P, Ndongo M (2012) "Methodology to size an optimal standalone P.V./wind/diesel/battery system minimizing the levelized cost of energy and the CO2 emissions". Energy Procedia 14:16361647.

[8] Dufo-López R, Fernández-Jiménez L, Ramírez-Rosado I, ArtalSevil J, Domínguez-Navarro J, Bernal-Agustín J (2017) "Daily operation optimisation of hybrid stand-alone system by model predictive control considering ageing model". Energy Convers Manag 134:167-177.

[9] Dali M, Belhadj J, Roboam X (2010) "Hybrid solar-wind system with battery storage operating in grid-connected and standalone mode: control and energy management-experimental investigation”. Energy 35(6):2587-2595.

[10] Gupta R, Kumar R, Bansal A (2015) "BBO-based small autonomous hybrid power system optimization incorporating wind speed and solar radiation forecasting". Renew Sustain Energy Rev 41:1366-1375. 